July 1985

\title{
A Patient with Aids
}

Susan Ball, MD

Thomas Jefferson University Hospital

Stephen Hauptman, DO

Thomas Jefferson University Hospital

Jean Helz, MD

Thomas Jefferson University Hospital

Sheila Murphey, MD

Thomas Jefferson University Hospital

Beth Shindell, MSS

Thomas Jefferson University Hospital

Follow this and additional works at: https://jdc.jefferson.edu/jeffjpsychiatry

Part of the Psychiatry Commons

Let us know how access to this document benefits you

\section{Recommended Citation}

Ball, MD, Susan; Hauptman, DO, Stephen; Helz, MD, Jean; Murphey, MD, Sheila; and Shindell, MSS, Beth (1985) "A Patient with Aids," Jefferson Journal of Psychiatry. Vol. 3 : Iss. 2 , Article 7.

DOI: https://doi.org/10.29046/JJP.003.2.011

Available at: https://jdc.jefferson.edu/jeffjpsychiatry/vol3/iss2/7

This Article is brought to you for free and open access by the Jefferson Digital Commons. The Jefferson Digital Commons is a service of Thomas Jefferson University's Center for Teaching and Learning (CTL). The Commons is a showcase for Jefferson books and journals, peer-reviewed scholarly publications, unique historical collections from the University archives, and teaching tools. The Jefferson Digital Commons allows researchers and interested readers anywhere in the world to learn about and keep up to date with Jefferson scholarship. This article has been accepted for inclusion in Jefferson Journal of Psychiatry by an authorized administrator of the Jefferson Digital Commons. For more information, please contact: JeffersonDigitalCommons@jefferson.edu. 


\section{INTERDISCIPLINARY CASE CONFERENCE:}

\section{A PATIENT WITH AIDS}

\section{SUSAN BALL, M.D., STEPHEN HAUPTMAN, D.O., JEAN HELZ, M.D., SHEILA MURPHEY, M.D., BETH SHINDELL, M.S.S.}

Susan Ball, M.D., Chief Resident: Mr. B, a thirty-five-year-old white male, was admitted to the medical service with chief complaints of fever, chills, and increasing shortness of breath. This was Mr. B's second admission. His first was six months ago for pneumonia, leukopenia, and lymphadenopathy of unknown etiology. At that time he was treated with antibiotics; he improved and was discharged. Since that time Mr. $\mathrm{B}$ reported continuing to feel weak and lethargic. Two weeks before this admission he noted the onset of fever, chills, sore throat, and a nonproductive cough. He initially saw a medical doctor for these complaints who diagnosed his problem as bronchitis and treated him with intramuscular injections that were probably antibiotic in nature. He continued to experience malaise and fever. Next he saw an otolaryngologist, who diagnosed Mr. B as having oral thrush. He was placed on Mycostatin Oral Suspension ${ }^{\circledR}$, but continued to experience increasing fever, chills, shortness of breath, and sore throat, as well as arthralgias, abdominal pain, and diarrhea. Shortly thereafter Mr. B was admitted to the hospital.

Mr. B's past medical history is remarkable for anemia and a hiatal hernia. Family history is remarkable for myocardial infarction and carcinoma. Social history revealed that the patient was an educator who denied tobacco use, admitted to occasional alcohol use, and denied any oral or intravenous drug abuse. He had been living with the same man for the past twelve years, but had had sexual partners outside the relationship up until a year prior to admission.

On physical examination Mr. B was a well developed Hispanic male who appeared acutely ill. He was in mild respiratory distress and was diaphoretic. Temperature was $103.5^{\circ}$. Pulse was 125 per minute. Respirations were thirty-six per minute. His blood pressure was $130 / 80$. Physical examination was remarkable for a white exudate on the posterior pharynx and white plaques on the roof of his mouth. The neck was supple without lymphadenopathy. The lungs displayed decreased breath sounds to auscultation with dullness to percussion at both bases; there were also rales bilaterally on auscultation. Mr. B's physical examination was otherwise unremarkable.

Pertinent laboratory studies included a complete blood count that showed a white count of $7.5 \mathrm{~K} / \mathrm{CUM}$, with 70 segs, 15 lymphocytes, one atypical lymphocyte, four monocytes, four eosinophils, and six stabs. Hemoglobin was $12.8 \mathrm{G} / \mathrm{DL}$. There was $1+$ anisocytosis. Arterial blood gases showed a $\mathrm{pH}$ of 7.52 , a $\mathrm{pO}_{2}$ of $55 \mathrm{~mm} \mathrm{Hg}$, a $\mathrm{pCO}_{2}$ of $33 \mathrm{~mm} \mathrm{Hg}$, and $92 \% \mathrm{O}_{2}$ saturation. On four liters of oxygen by nasal canula the patient's $\mathrm{pO}_{2}$ went up to $106 \mathrm{~mm} \mathrm{Hg}$. Chest X-Ray revealed bibasilar interstitial disease and blunting of the costophrenic angles, with a possible small pleural effusion.

Mr. B was seen by Hematology, Infectious Diseases, and Otolarygology. He underwent transbronchial biopsy which revealed Pneumocystis carinii. He was started on Bactrim ${ }^{\circledR}$ and a provisional diagnosis of Acquired Immune Deficiency Syndrome (AIDS) was made. Hematology, who had seen the patient on his previous admission, found that he had diminished OKT4 and OKT8 ratios. Following that the diagnosis of AIDS was felt to be well established.

Mr. B had persistent nausea and anorexia in the hospital which was felt to be caused by pancreatitis that may have been a side effect of Bactrim ${ }^{\circledast}$. His amylase level at one point was as high as 463 Somogyi units $/ 100 \mathrm{ml}$. Mr. B's pancreatitis was treated symptomatically. By the time of discharge this problem had resolved. 
with ARC who have existing immunological abnormalities do not change, that is to say, they do not appear to get better or get worse. We do not know what will happen over the long run, ten or fifteen years.

As of October 1, 1984, the CDC reported that the number of cases of AIDS continues to double every six months. As of November 6,1984, the number of cases was 6,993. We are now undoubtedly over 7,000. The distribution of AIDS is as follows. California and New York are reporting the highest number of cases. Texas, Florida, and New Jersey are the second tier of states, reporting the next highest incidence of AIDS. In the third tier of states are Pennsylvania, Ohio, Michigan, Indiana, Iowa, Arkansas, Virginia, Georgia, Louisiana, Colorado, Arizona, and Washington. A common denominator for these states is the presence of a large metropolitan area, where the greatest number of cases occur.

Roughly three-quarters of patients (about $72 \%$ ) with AIDS are homosexual or bisexual men (in the United States, not necessarily in other parts of the world). Roughly seventeen percent are parenteral drug abusers. Roughly four percent are of Haitian origin. One may argue that there is a significant area of overlap between these groups. The epidemiological data that is accumulating on the human T-leukemia virus III (HTLV-III) suggests that it is important to recognize that some ethnic groups, because of their origin, may be at greater risk than others. One percent of AIDS cases nationwide occur in hemophiliacs; the incidence in patients with hemophilia is much higher than in other risk groups. Patients who are heterosexual contacts of members of other known risk groups represent one percent of those with AIDS. Transfusion related cases account for one percent of all cases. Unknown or other are four percent of the total; this four percent includes pediatric patients, some who died before appropriate interviews and investigations could be carried out, and some for whom no risk characteristics are known.

Over a third (37\%) of all cases of AIDS are reported to occur in New York City. San Francisco reports twelve percent, Los Angeles eight percent, Miami four percent, and Newark three percent. These are figures valid through October 1,1984 . AIDS is primarily a disease of urban areas and their surrounding counties at this time.

With regard to case presentation, those patients who present with Kaposi's sarcoma instead of an opportunistic infection seem to have a somewhat better prognosis. This presentation is more common in those patients in the largest risk group, men who are homosexually or bisexually active.

There are no great surprises in the breakdown of racial and ethnic statistics, except that in a few cities there is a disproportionate percentage of AIDS in Blacks. These cities include Philadelphia, Washington, and Baltimore. This may have to do with the epidemiology in different populations in different urban areas.

Female patients with AIDS are primarily members of the intravenous drug abuse risk group, or have contacts with bisexually active men or intravenous drug abusers.

Again, there is frequently an overlap between risk groups. The CDC catagorizes these patients by their major life style risk, e.g., they are predominately drug abusers with little homosexual contact or predominately homosexually active men who infrequently abuse drugs.

AIDS is a venereal disease which is transmitted by sexual contact. Like many venereal diseases, it may be transmitted by the parenteral route as well. Parenteral drug abuse, transfusion of contaminated blood products, and blood contamination of body secretions at the time of intimate contact may all be responsible for the spread of AIDS.

There is a small group of patients with AIDS who do not appear to belong to any of the major risks groups, that is to say, they are not male homosexuals and bisexuals, intravenous drug abusers, hemophiliacs, or Haitians. In that group a significant portion are actually sexual contacts of members of major risk groups. Some of them are the children of mothers who are members of risk groups; a few of them are children whose mothers appear to be normal, but whose fathers are members of risk groups.

The older a case of AIDS is in terms of the date of diagnosis the more likely it is that the patient will have expired. Ultimately we believe that AIDS will probably be an entirely fatal disease. Patients presenting with an opportunistic infection, such as $P$. carinii pneumonia, are usually dead within one year of their diagnosis. The patients who live longest are those who present with Kaposi's sarcoma and do not develop an opportunistic infection, at least not early in their course.

In Philadelphia the number of cases of AIDS continues to double each quarter. Looking at national statistics, one sees a similarly alarming rise in cases being reported around the country. In New York state 
half of the reported cases come from New York City. This is an example of AIDS as primarily an urban disease (likewise in California, where two-thirds of all reported cases come from San Francisco).

As of July 1984, there have been 421 reported foreign cases of AIDS. These reports are the result of passive surveillance in most foreign countries. The majority of foreign cases being reported come from Europe because they probably recognize more cases. AIDS is probably, however, a worldwide disease.

The primary pulmonary infections in patients with AIDS are $P$. carinii pneumonia, pulmonary cytomegalovirus infections, and pulmonary $M$. aviumintracellulare infections. Mucosal infections are very debilitating to the patient. They are difficult to control, make the patient's life miserable, and may interfere with his nutritional status. An example is severe perianal herpetic disease, something that is a serious medical problem and makes the patient extremely uncomfortable.

Central nervous system infections in patients with AIDS are frequently fatal. They include toxoplasmosis, cryptococcal meningitis, progressive multifocal leukoencephalitis, cytomegalovirus encephalitis, and central nervous system aspergillosis.

Cryptosporidiosis and giardiasis are common gastrointestinal infections in patients with AIDS which may cause severe diarrhea and malabsorption. We can treat the giardiasis, but it is very difficult to effectively treat the cryptosporidiosis. Long term parenteral hyperalimentation is sometimes required because of the severity of the malabsorption.

Chorioretinitis in patients with AIDS is usually a result of a cytomegalovirus infection, although occasionally other entities may cause this problem as well. Often this will leave the patient blind.

Malignancies which are not recognized to produce systemic immunosuppression, but are considered to result from the immunosuppression that occurs in AIDS are Kaposi's sarcoma and CNS lymphoma — a very rare entity. The presentation of Kaposi's sarcoma can be very variable; lesions can be both visceral and cutaneous, unlike the usual presentation of Kaposi's sarcoma occurring in the otherwise older healthy male as cutaneous lower extremity lesions. Typical lesions may occur on the heel, chest, palate, or in the gastrointestinal tract.

Other malignancies are probably also occurring with increasing frequency, at least in the homosexual and bisexual population. Whether or not this is truly related to AIDS remains unclear. We cannot presently diagnose AIDS in a patient with systemic lymphoma, which produces its own immunosuppression.

Rather poorly effective therapy is available for patients with $M$. avium infections, cryptosporidiosis infections, and Kaposi's sarcoma. We have no therapy presently for patients with progressive multifocal leukoencephalopathy, idiopathic encephalopathy, cytomegalovirus infections, Epstein-Barr virus infections, or the renal insufficiency that occurs in five to ten percent of AIDS patients. We can treat things like cryptococcal meningitis, but patients tend to relapse as soon as therapy is stopped. We can treat $P$. carinii infections, but again, patients tend to relapse. Also, the treatments themselves often have serious complications, such as the leukopenia that may result from Bactrim ${ }^{\circledast}$.

AIDS is a venereal and blood borne disease. It can be spread by sexual contact, as well as by contact with blood products. Whether other secretions can transmit the disease is unclear at this time. In patients with AIDS Related Complex, the HTLV-III virus has been found in saliva and in semen.

Recommendations are that patients who are members of known risk groups should not donate blood. They should be very circumspect about sexual contact with others. If they have AIDS, they should not have sexual contact or at least should explain to their partner that they have AIDS. Even if an antibody assay for HTLV is put into use, this will not with one hundred percent efficiency guarantee the safety of the blood from a transmittable agent. For this reason, we are going to continue to recommend for some time that members of known risk groups do not donate blood regardless of the availability of an antibody assay.

Isolation in the hospital of patients with AIDS is directed against the known means of transmission. Because it is a blood borne disease, patients have to be on blood and body fluid precautions. In this hospital, because we still use enteric precautions for patients with hepatitis, we also use it for patients with AIDS. The majority of patients with AIDS do have symptomatic diarrhea. Private rooms are needed only for patients who do have problems with their enteric secretions. In many hospitals enteric precautions are not routinely used.

Any contact with the blood or bodily secretions of a patient with AIDS is potentially hazardous. Materials that have been contaminated need to be sterilized or disposed of properly. With the appropriate 
precautions, as is outlined in the hospital isolation manual, it is perfectly safe to perform any necessary diagnostic or therapeutic procedure on these patients. The major logistical problem is that if you have to do hemodialysis then that machine should be used only on patients with AIDS.

HTLV-III, a retrovirus, a member of a large family of viruses, is thought to be on fairly good (but not absolute) evidence at this time to be the probable causative agent in AIDS. Unlike HTLV-I, which has been found in a small number of patients with AIDS and AIDS Related Complex, this virus has been isolated from thirty to fifty percent of patients with AIDS and some patients with AIDS Related Complex. Antibody evidence of infection with this virus has been found in ninety-one percent of patients with AIDS and ninety-eight percent of patients with AIDS Related Complex. About fifty percent of a population of hemophiliacs screened gave evidence of similar exposure. Between fifty to eighty percent of patients who were healthly and homosexually or bisexually active have been found to have antibodies to this agent. It has also been found in mothers of babies with AIDS, the babies themselves, and members of high risk groups whose blood is known to have caused AIDS. Other so called low risk groups have been antibody negative to date.

HTLV-III is a lymphotropic virus that preferentially infects T4 cells. It is the loss of T4 cells that is largely felt to be responsible for the immunologic defect in patients with AIDS. Interestingly, this is a virus that prefers to infect activated T-cells rather than nonactivated T-cells. This is probably of some importance because the lifestyle of homosexually and bisexually active males may make them more immunologically activated. Similarly, hemophiliac patients may also be immunologically turned on.

In foreign countries, particularly in the Caribbean nations and Central Africa, it has been noted that fewer of the patients recognized appear to be members of known risk groups in the U.S. If you examine those patients who do not appear to be members of known risk groups, a large number are heterosexually, as well as homosexually, promiscuous. There does appear to be a correlation between multiple sexual partners in those patients and the likelihood of developing AIDS. In a small population studied in Central Africa, there was a high incidence of HTLV-III antibody in the group of prostitutes studied. Those patients who themselves are not promiscuous who develop AIDS are frequently the contact of sexually promiscuous persons.

If HTLV-III virus is the cause of AIDS, then we are developing assays that can predict prior exposure to the virus. We don't know exactly what exposure to the HTLV-III virus means at this time. Many people who have evidence of exposure to this virus are healthy; they are not even minimally symptomatic. Some of these people will probably never develop disease. Some may develop illness later. Some patients who develop mild symptoms may not progress to more serious disease. So at this time we don't know how to use an antibody assay of HTLV-III virus except to screen potential blood donors. Again, the use of the assay in this way will be helpful, but does not guarantee one hundred percent protection against the transmittable agent.

Knowing the virus may eventually enable us to develop a vaccine, but I suspect that progress in this area will be much slower than initially predicted. We don't know that a killed virus vaccine will be protective, and I don't think that anyone will want to take a chance on a live attenuated virus vaccine at this time. Dr. Hauptman, would you comment on this case, please?

Stephen Hauptman, D.O., Professor of Medicine, Cardeza Foundation: There are two points that I would like to make. First, it has recently been proposed that HTLV-III, a retrovirus, is the cause of AIDS. A retrovirus is an RNA virus, one that has in its genome a gene that controls a protein that we call reverse transcriptase. The virus infects the cell, making its own reverse transcriptase. It then takes nucleotides from the host cell and makes its own copy of DNA. This copy is frequently, but not always, incorporated into the DNA of the host. It may be integrated in one spot or a number of spots. In the case of AIDS and HTLV-III, it would appear to be integrated into a number of spots.

What put investigators onto the study of retrovirus is a disease called feline leukemia, which is also due to a retrovirus and produces either a leukemic syndrome or an immunodeficiency syndrome-manifested by opportunistic infections. Secondly, HTLV-I has been highly associated with an adult T-cell leukemia that is not found in this country. In the United States most adult T-cell leukemias are not associated with HTLV-I. Patients with HTLV-I associated adult T-cell leukemia, much like feline leukemia, frequently have opportunistic infections.

Last year there was a published report of HTLV-I having been isolated in a small number of patients with AIDS (1). Simultaneously, there was another report that a significant percentage of patients with 
AIDS had antibodies to the HTLV-I virus (2). At the time it was felt that HTLV-I might be the cause of AIDS. As time went on, it was found that an increasingly smaller number of AIDS patients had the HTLV-I virus. Now we know that the antibody to HTLV-III happens to cross-reaction to HTLV-I. So, one thing we know for sure is that HTLV-I is not the cause of AIDS. These patients, by the way, have lots of viruses that can be isolated.

Subsequently, the HTLV-III virus was isolated in eighty-five percent of patients with AIDS and seventy-five to eighty percent of patients with the associated lymph node enlargement syndrome (3). As an aside, the lymph node enlargement syndrome associated with AIDS is frequently called Pre-AIDS. I don't like this name because only a small portion with lymph node enlargement or wasting syndromes will actually go on to develop AIDS. In fact, only three or four percent of these patients will develop AIDS (4).

To show that HTLV-III infects a cell, you have to do something unusual. You have to activate the cell with a mitogen. That was the stumbling block that kept researchers from discovering this possible cause of AIDS sooner. First, you would take T-cells, activate them with PHA, add a growth factor, and then in two weeks you could isolate the virus using electron microscopy or antibodies. It should be noted that if you wait a month you get no virus; the cells all die out.

Initially researchers were unable to isolated HTLV-III or find significant antibody titers in healthy homosexual males. This is in contrast to AIDS patients and those with the associated lymph node enlargement syndrome, of whom at least eighty percent have been found to have significant antibody titers (5). Later reports, however, have found that between fifty to sixty percent (depending on the area) of healthy homosexual males will react to HTLV-III antibody (6). Ninety percent of hemophiliacs have antibodies to HTLV-III. In a recent report, this virus was isolated from the semen, blood, and saliva of six out of eight healthy homosexual males $(7,8)$. Although this was a small study, if HTLV-III is the cause of AIDS, then the implication is that there are a tremendous number of carriers.

With that background, let's discuss two areas that might indicate HTLV-III is not the AIDS virus. Firstly, one reason to doubt HTLV-III as the virus that causes AIDS is that up until April 1984, attempts to infect chimpanzees with the AIDS virus had been unsuccessful. Although these chimps did not develop AIDS, they did develop a decrease in the T-4 to T-8 ratio, which isn't diagnostic. Sunlight will do the same to that ratio. One of the chimps developed a transient lymph node enlargement. They all developed antibodies to the HTLV-III virus. Now, more than a year-and-a-half later, it has not been possible to produce an AIDS like syndrome in chimps, despite injecting them with HTLV-III from an infected cell line. There is a disease termed simian AIDS, but this is only transmissible from ape to ape. To date, it has not been shown that human AIDS can be transferred to chimps.

Secondly, if you activate T-4 (helper) and T-8 (killer) cells in the peripheral blood, then only a small percentage of T-4 cells will become infected upon exposure to HTLV-III. Over the past year, however, we have shown that T-8 cells are defective in AIDS patients, perhaps just as defective as T-4 even though they are not infected (9).

Another point that is important is that you can isolate many viruses from the AIDS and ARC groups we've been discussing. This should foster a healthy skepticism. For example, CMV can be isolated with roughly the same frequency as HTLV-III in healthy gay men, lymph node enlargement syndrome, and patients with AIDS. The same is true for Epstein-Barr virus and many kinds of herpes viruses, as well as the antibody for hepatitis B virus.

To my knowledge, no one has tried to infect activated T-4 and T-8 cells with other viruses, for example, CMV and hepatitis B virus. Neither have other types of cells, for example, smooth muscle or heart cells, been activated and then infected with HTLV-III to see what would happen.

I think there is enough evidence for us to be suspicious that HTLV-III might not be the virus. I'm not saying that HTLV-III isn't the virus. Maybe it is. But we need more evidence to be sure.

A treatment that we have been trying here for AIDS patients is lymphocyte transfusions. In our experience, if these infusions are given once a month they seem to prolong the lives of AIDS patients who have received them. Our first patient in this program, who received his first infusion over two years ago, just died from a CNS lymphoma. He did not die from a recurrent infection. None of the patients we've transfused have had recurrences of their infections.

We can only begin to speculate on the mind-body connection and how this may influence AIDS. We know that in the patient presented here today that his mother had died in the recent past. Did this make his 
immune system more susceptible to AIDS? Whatever the connection, we all know how important psychological and social support can be to AIDS patients. Ms. Shindell, could you comment on the role of the AIDS Task Force, please?

Beth Shindell, M.S.S., AIDS Task Force: Thank you, Dr. Hauptman. I would like to talk to you about the role of the AIDS Task Force here in Philadelphia. Our organization was founded by a small group of gay professionals about two years ago. We have grown to an organization of several hundred members that is able to provide a variety of services.

Our organization has several roles. One of our functions is to provide service management for people with AIDS. That means that we have a group of social workers who will — only on referral — see what the patient needs. We have buddies who will provide direct services, for example, grocery shopping. We also have clinical psychologists, psychiatric social workers, and psychiatrists on our staff who provide direct clinical care to persons with AIDS. We have just started two support groups, one for persons with AIDS and one for their friends and families.

Another important role of the AIDS Task Force is in educating the professional and lay community about AIDS. We have a research committee that keeps abreast of the latest AIDS research, as well as an advocacy committee that seeks to address the severe forms of discrimination that may be directed against persons with AIDS. For example, at the present time there is no nursing home in the city of Philadelphia that will accept someone with AIDS. Finally, we have a small fund, the John Locke Memorial Patient Support Fund, that can be used for persons with AIDS who are in dire need of financial assistance for housing and clothing, transportation, or other needs.

I am glad to be a part of this conference. Unfortunately there are some hospitals where our presence is not welcome. This may derive from a misconception that our organization is not professional in nature. Quite the contrary is true. Indeed, our continued success depends upon the dedication of outstanding professionals like Dr. Ifft.

I would like to discuss briefly the impact of AIDS upon the gay community, which is the largest risk group. First of all, the gay community is approximately half men and women. Gay women are not in the risk group, unless they are sexual partners with bisexual men or are IV drug abusers.

The impact of AIDS on the gay community has been tremendous. AIDS impacts people who are in the prime of their life and face the loss of their jobs, health benefits, and lives. Many profound emotions are stirred whenever there is a loss within the Task Force or the community. Because of this, AIDS has to some extent acted as a cohesive force in pulling the gay community together.

One of the few positive outcomes of this disease may be the desensitization of the larger community to their gay neighbors. There are people who are using the term homosexual and gay who never would have before.

If anyone would like further information about the AIDS Task Force, we have several brochures available, as well as an AIDS Hotline, 215-232-8055. Our address if you would like to write is: The Philadelphia AIDS Task Force, P.O. Box 7259, Philadelphia, PA 19101.

Jean Helz, M.D., Assistant Director, Division of Consultation and Liaison Psychiatry: Thank you, Ms. Shindell. The psychiatric concomitants of this disease are very important. Whenever you have an illness that's seen as universally fatal occurring in young people who are about the same age as their health care givers, a lot of conflictual feelings arise. I think that one important and potentially dangerous manifestation of this is denial among health care givers. We were called to see a patient who complained of headaches. His primary care takers felt that his headaches were psychosomatic based on his impending discharge home. The patient was an AIDS victim who was severely ill. His headache had no psychosomatic features whatsoever. After we left the room, the patient had a grand mal seizure. As it turned out, this patient had a CNS cryptococcal infection.

Several factors may have gone into this patient's physician's inability to recognize that his complaints of headaches were related to true physical disease. Part of it was a wish that his symptoms would be psychosomatic so that he could go home. In other words, the physician did not want to believe that the patient was as ill as he really was.

Another important issue is the inability of some physicians to even communicate the diagnosis of AIDS to their patients. This is an issue that also arises in the treatment of some cancer patients.

Dr. Hauptman: There is a study that was done in which two groups of patients were and were not told of their 
diagnosis of cancer (10). What they found was that the patients who had been told that they had cancer lived significantly longer than the group of patients who did not know.

Dr. Helz: In practice, we often suggest that each patient's physician follow the hints that their patients give them. There are patients who do not want to know their diagnosis and will block out whatever you tell them. How do you deal with telling an AIDS patient that they have AIDS? Is there any hope that you can offer them?

Ms. Shindell: Isn't the matter of the patient knowing his own diagnosis complicated by the amount of education that has taken place among high risk groups? I mean, I am surprised that in the case presented that the patient did not know that Pneumocystis carinii is indicative of AIDS.

Dr. Hauptman: No, I'm not sure that they get the details. A lot of my patients are very bright and aware, but do not know any particulars about the disease, for example, Pneumocystis carinii. A lot of this information may be buried because of the tremendous amount of information that is available.

Dr. Ball: What about the attitude of hospital staff towards taking care of patients with AIDS? What is that like?

Dr. Murphey: Staff attitude is much better than it was when we got our first few patients. There used to be a lot of paranoia and panic. It varies from floor to floor and unit to unit.

Ms. Shindell: People who will care for an AIDS patient in the hospital will be reluctant to care for them at home, perhaps because they feel there is less control over the disease at home. In my experience, the first time anyone comes into contact with an actual case of AIDS they often experience feelings of panic.

Dr. Ball: What was it that changed the attitude of the staff towards patients with AIDS?

Dr. Hauptman: The hospital administration asked Dr. Murphey, myself, and two or three other people to educate and desensitize hospital staff, including everyone from housekeeping staff to residents.

Dr. Ball: What is the life expectancy of someone with AIDS?

Dr. Hauptman: In Philadelphia, two months. Eighty-five to ninety percent of patients are dead within six months in the metropolitan Philadelphia area.

Dr. Murphey: What happens with these patients is that they get one opportunistic infection after another on top of another. Patients who are not dead after two months tend to have prolonged, difficult hospital courses. The patient mentioned who had cryptococcal meningitis is an example. He was in the hospital for all but a couple weeks of the last seven months of his life. Our first case was in the hospital for four months. Our second case was in the hospital for the better part of three months before he died. If a patient has to be hospitalized sixty days, his or her hospital costs may be as much as one million dollars. AIDS is a devastating disease, not only to the patient and his family, but also the health care system as a whole, which is one good argument for directing our research efforts against this disease.

Dr. Helz: From a liaison psychiatry standpoint, it is clear that AIDS is a disease that stresses every level of the health care system. In university hospitals I think it is very important that these patients have a primary physician who coordinates health care efforts. Often patients can feel lost amid the myriad of consultants who may be working on these often very difficult cases. It is very important in these cases for the patient to have one physician who he can identify with.

Another serious issue is the homophobia that exists among some treating physicians. We can only hope to identify this on an individual basis and gradually convince these physicians that their attitude may compromise the patient's health care. Conferences such as this are useful in providing for an optimal level of exchange among physicians and health care workers.

\section{REFERENCES}

1. Gallo R, Sarin P, Gelmann EP, et al: Isolation of human t-cell leukemia virus in acquired immune deficiency syndrome. Sci 220: 865-867, 1983

2. Essex M, McLane MF, Lee TH, et al: Antibodies to cell membrane antigens associated with human t-cell leukemia virus in patients with AIDS. Sci 220: 859-862, 1983

3. Popovic M, Sarngadharan MG, Read E, Gallo R: Detection, isolation, and continuous production of cytopathic retroviruses (HTLV-III) from patients with AIDS and Pre-AIDS. Sci 224: 497-500, 1984 
4. Cassens B: personal communication

5. Schupbach J, Popovic M, Gilden R, et al: Serological analysis of a subgroup of human t-lymphotropic retroviruses (HTLV-III) associated with AIDS. Sci 224: 503-505, 1984

6. Groopman J, Salahuddin Z, Sarngadharan MG, et al: HTLV-III in saliva of people with AIDS-related complex and healthy homosexual men at risk for AIDS. Sci 226: 447-449, 1984

7. Zagury D, Bernard J, Leibowitch J, et al: HTLV-III in cells cultured from semen of two patients with AIDS. Sci 226: 449-451, 1984

8. Ho D, Schooley R, Rota T, et al: HTLV-III in the semen and blood of a healthy homosexual man. Sci 226: 451-453, 1984

9. Hauptman SP, Ebert EC, Stoll DB, Cassens BJ, Lipshutz WH: Diminished interleukin-II production and receptor generation characterizes the acquired immune deficiency syndrome. (In press)

10. Fergson M: The Aquarian Conspiracy: Personal and Social Transformation in the 1980's. Los Angeles, Tarcher, 1981 